\title{
Technical News Briefs
}

\section{New Technical Developments}

\section{COMPOSITE FILLINGS IMPROVED BY GLASS INSERTS}

A new dental technique using glass inserts in composite fillings has been developed at the American Dental Association Health Foundation (ADAHF) research center at NBS [1]. With the new method, cavities in teeth are first partially filled with an unhardened paste of composite resin. Inserts of a special alumino borosilicate glass are then pressed into the composite paste so that the inserts make up most of the volume and surface area of the final restoration. Excess composite is removed and the paste containing the inserts is hardened by a dental curing light, a device commonly used to harden composite materials. The light sensitive composite material hardens in approximately twenty seconds. The filling is then contoured and polished in the usual way.

Inserts are expected to decrease the effects of polymerization shrinkage, increase stiffness, decrease the coefficient of thermal expansion, and improve the durability of composite restorations. Thus, the properties would more closely match those of natural teeth than conventional materials. It is anticipated that they can be made in a variety of shapes and sizes with a range of shades and colors that closely match tooth enamel. Moreover, research at the NBS/ADAHF laboratories has shown that the inserts may improve the bonding of composite materials to tooth structures.

It is anticipated that biocompatibility will not be a problem, because the composition of the inserts is very similar to that of composite filler materials currently in use. Preliminary tests of feasibility have recently been initiated on volunteer patients in the NBS/ADAHF clinic and results to date are promising.
For further information contact R. L. Bowen, National Bureau of Standards, Gaithersburg, MD 20899.

\section{Reference}

[1] Bowen, R. L., and L. E. Setz, Posterior Composite Restorations with a Novel Structure, Joumal of Dental Research, 65, 797 (1986) (Abstract 642).

\section{FIRST NMR OF A RARE EARTH IMPURITY IN A RARE EARTH HOST}

The first Nuclear Magnetic Resonance (NMR) of a rare earth impurity in a rare earth host has been performed in a collaborative experiment between NBS and the Freie Universitaet Berlin and Bonn Universitaet [1]. In these experiments, the resonance of oriented radioactive terbium- 160 has been observed in a single crystal of terbium. This ferromagnetic system, in addition to having a very large nuclear magnetic dipole interaction, has a very large electric quadrupole interaction. Thus, the single dipole line is split into widely spaced subresonances. By measuring these subresonance frequencies one can obtain very precise values for both nuclear magnetic dipole and electric quadrupole moments. Information can also be obtained about the magnetization at the surface of the single crystal. The system of terbium- 160 in a terbium single crystal can also be used as an absolute thermometer over a wide range of temperatures and in a very large magnetic field.

\section{Reference}

[1] Roman, P.; W. D. Brewer, E. Klein, H. M. Marshak, K. Freitag, and P. Herzog, Magnetic Resonance of 160Tb Orientated in a Terbium Single Crystal at Low Temperatures, Phys. Rev. Ltrs., Vol. 56, 1976-1979, 1986.

\section{VAPORIZATION DATA FOR NUCLEAR WASTE}

Plans for storage of industrial nuclear waste including incorporating nuclear "sludge" in borosilicate glass at temperatures of $850-1150^{\circ} \mathrm{C}$. Plant experi- 
ence has indicated that there is some radionuclide loss, particularly of cesium, because of vaporization during the vitrification process. NBS scientists have completed a study which provides details of the phase and chemical transformations that occur during the initial steps of waste incorporation into a borosilicate glass host $[1,2]$. The work was sponsored by the Dupont Atomic Energy Division, which needed the data for the development of the vitrification process.

Specialized mass spectrometric and thermogravimetric techniques were used to monitor the vapor transport of species over a range of temperatures and compositions. These included the "transpiration mass spectrometer" developed at NBS, in which vapor pressures are determined from observed ion currents using the known carrier gas pressure as reference.

The nuclear waste "sludge," consisting mainly of insoluble oxides and hydrous oxides, has thighly complex chemical and phase characteristics. Because of this complexity, it was necessary to obtain data on individual component compounds, as well as on the sludge itself. For example, because vapor pressure data and thermodynamic functions for many component compounds were unavailable or unreliable, attention had to be given to the determination of the vaporization characteristics of key cesium containing compounds (nonradioactive isotopes) as well as to the vaporization behavior of synthetic sludge and sludge incorporated in borosilicate glass.

The results of the study indicate a variety of modes by which cesium can be lost to the vapor phase during the nuclear waste glass encapsulating process. The degree of cesium vapor transport will depend on the temperature history of the vitrification process. It was also seen that the loss of cesium to the vapor phase is enhanced by the presence of carbon, halogen, or watervapor.

Thermodynamic mixing models based on the results of the study will be combined with a solution model previously reported by the NBS scientists to model the plant scale process.

\section{References}

[1] Plante, E. R, and J. W. Hastie, Vaporization and Phase Equilibria of Simulated Radionuclides, NBSIR 863348 (1985).

[2] Hastie, J. W.; E. R. Plante, and D. W. Bonnell, Vaporization of Simulated Nuclear Waste Glass, NBSIR 832731 (1983).

\section{LEVITATION CALORIMETRY OF}

\section{REFRACTORY MATERIALS: TUNGSTEN}

An experimental interaction among groups at the National Bureau of Standards, General Electric
Space Facilities Laboratory (Valley Forge, PA), and Rice University (Houston, TX), supported by the National Aeronautics and Space Administration, has had the purpose of exploring the limits of ground based high temperature levitation research. This work developed an ultra-high temperature calorimeter system coupled to an electromagnetic levitation/electron beam heating facility [1] which yielded the first direct calorimetric value for the enthalpy of fusion $(\Delta \mathrm{Hm}(\mathrm{W}, 3695))$ of tungsten $[2,3], 53.0 \pm 2.3 \mathrm{~kJ} / \mathrm{mol}$. The value for the enthalpy of fusion is higher by nearly 50 percent than the value estimated from the Tamman rule, which states that $\Delta \mathrm{Sm}=9.6 \mathrm{~J} / \mathrm{mol} . \mathrm{K}$ for metal elements. The Tamman rule is currently the basis for the value of the enthalpy of fusion in use for tungsten as well as for many other refractory metals. However, the experimental result is in accord with periodic correlation estimates which indicate that the entropy of melting, $\Delta \mathrm{Sm}$, should be somewhat higher than the fusion entropy for molybdenum $(12.9 \mathrm{j} / \mathrm{mol} . \mathrm{K})$. This experimental fusion enthalpy corresponds to a value for $\Delta \mathrm{Sm}$ of $14.3 \pm 0.6 \mathrm{~J} /$ mol.K, 11 percent larger than molybdenum, and in excellent agreement with results of a recent $\mathrm{Eu}-$ ropean study [4]. The new experimental value should serve as a benchmark for testing new phase transition theories and molecular dynamics models, including high temperature melting.

In addition to providing thermophysical property data at ultra high temperatures, the research has also demonstrated proof of concept for levitation of molten materials in space. Joint development and testing of a prototype apparatus for space flight calorimetry [5] (the "gulp" calorimeter), a prototype two color imaging pyrometer [1-2], and various other aspects of the process of developing experimental apparatus for high temperature calorimetry in the microgravity environment of space $[3,7,8]$ has been accomplished.

\section{References}

[1] Bonnell, D. W., in NBS: Materials Measurements, NBSIR 81-2285, ed. J. R. Manning (NBS, Gaithersburg, MD, 1981).

[2] Bonnell, D. W., in NBS: Materials Measurements, NBSIR 84-2882, ed. J. R Manning (NBS, Gaithersburg, MD, 1984).

[3] Bonnell, D. W., in NBS: Materials Measurements, NBSIR 85-3217, ed. J. R. Manning (NBS, Gaithersburg, MD, 1985).

[4] Arpaci, A., and G. Frohberg, Z. Metallkd. 75, 614-618 (1985).

[5] Bonnell, D. W., in NBS: Materials Measurements, NBSIR 83-2772, ed. J. R. Manning (NBS, Gaithersburg, 1983).

[6] Frost, R. T., and E. Stockoff, Final Report, NASA Contract NAS8-34231 Task 7 (General Electric Space Systems Division, Valley Forge, PA, 1983).

[7] Bonneli, D. W., in NBS: Materials Measurements, NBSIR 82-2560, ed. J. R. Manning (NBS, Gaithersburg, MD 1982).

[8] Bonnell, D. W., in NBS: Materials Measurements, ed. J. R. Manning, Annual Report, NASA Contract H27954B (NBS, Gaithersburg, MD, 1986). 


\section{CHARGE DENSITY WAVES OBSERVED IN A SIMPLE METAL}

The first direct evidence for the existence of charge density waves in a simple metal, potassium, has been produced by scientists from Purdue University, the University of Missouri, and NBS. The experiments utilized the high-resolution neutron diffraction facility at the NBS Research Reactor to observe very weak satellite peaks in a highly perfect potassium crystal.

The experiments confirmed the theory put forth by one of the authors that the free electrons do not remain uniformly distributed, as held by more conventional theories. The new theory, proposed by Overhauser of Purdue, suggests that the electron density varies sinusoidally with a characteristic charge density wave that is not an integral multiple of the metal lattice constant. The location, intensity, and geometrical arrangement of the charge density wave peaks observed in the NBS experiments are in good agreement with the predictions of the theory.

References

[1] Giebultowicz, T. M.; H. W. Overhauser, and S. A. Werner, Phys. Rev. Ltrs., 56, 1485 (1986).

\section{EXPANDED VERSION OF IGES STANDARD \\ FOR CAD DATA AVAILABLE}

NBS has released a new, extended version of the popular Initial Graphics Exchange Specification (IGES), a standard data format designed to simplify the exchange of computer-generated design information between otherwise incompatible CAD systems [1].

The updated specification, Version 3.0, contains expanded capabilities for representing part geometries, new capabilities to allow for creating standard "libraries" of parts, and a new method of reducing the size of IGES files. The new version also includes many clarifications and refinements to the IGES standard based on experience with using an earlier version of IGES across a wide variety of CAD systems.

The original IGES was developed in 1979 under sponsorship of the Air Force Integrated ComputerAided Manufacturing Program. The specification defines a computer file format for the storage of three dimensional geometric information and twodimensional drawing information that is created by CAD systems.

Data can be exchanged between two otherwise incompatible CAD systems by using pre and postprocessors to translate the data out of the first CAD system into the IGES format, and out of the IGES format into the second system.
Department of Defense and National Aeronau tics and Space Administration procurement specifications routinely require the use of IGES, and IGES translators are available as options from every major U.S. CAD-system manufacturer.

IGES is managed by a joint industry-government group coordinated by NBS. The first version of IGES was adopted by the American National Standards Institute (ANSI) as a major portion of its standard Y14.26M. Version 3.0 was submitted to ANSI in March 1986.

In addition to clarifying several aspects of earlier versions of the standards, IGES Version 3 adds new capabilities in geometry for Offset Curves, Offset Surfaces, and Curves on a Parametric Surface. A Trimmed Surface entity allows for the definition of surface boundaries, and new capabilities in annotation have been added.

IGES 3 introduces greatly enhanced capability for user defined MACROS essential for creating standard part libraries of symbols and components.

IGES 3 also introduces a method of reducing IGES files to one-third of their previous size, using a Compressed ASCII Format, to save on storage space and telecommunications costs.

While continuing to upgrade and improve the graphics exchange standard, the IGES organization has also begun work on a Product Data Exchange Specification (PDES), which will allow a complete product model database to be exchanged and used directly by advanced computer integrated manufacturing programs such as automatic process planning or inspection systems.

Information such as manufacturing features, tolerance specifications, material properties, and surface finish specifications will be made available to application programs in the PDES format.

IGES technical meetings are held regularly throughout the year to discuss enhancements and modifications to the IGES standard. The next meeting is scheduled for the week of October 20 in Huntsville, AL. Interested persons are invited to contact Mrs. Gaylen Rinaudot, the IGES coordinator, A353 Metrology Building, National Bureau of Standards, Gaithersburg, MD 20899, Telephone 301-921-3691.

\section{Reference}

[1] Initial Graphics Exchange Specification (IGES), Version 3.0 (NBSIR 86-3359), National Technical Information Service, Springtield, VA 22161 ( $\$ 40.95$ prepaid. Order by PB\# 86-199759. Microfiche copies are also available).

\section{COMPUTER PROGRAM EVALUATES HEAT DETECTORS}

NBS researchers have developed a computer program to evaluate heat detection systems installed in 
existing buildings. Depending on ceiling height, spacing of detectors, type of detector, and how fast the fire grows, the program will determine how long it will take for the detector to be activated. The user-friendly program is available in both BASIC and FORTRAN and will run on both mainframes and personal computers. An extensive set of tables which can be used to quickly evaluate response times of common systems has been generated. A 557-page NBS Special Publication [1] includes the program as well as the tables. It also gives practical examples on using the tables and computer program.

Reference

[1] Evaluating Thermal Fire Detection Systems (SP 712), Superintendent of Documents, U.S. Government Printing Office, Washington, DC 20402. (\$25 prepaid. Request stock no. 003003-02727-8.)

\section{KEY PAPERS AVAILABLE ON STANDARDS} AND MEASUREMENT OF ELECTRICITY

NBS has published a compilation of key papers by NBS authors on electrical measurements [1]. The volume includes 66 papers published during the last two decades, including many published in recent years on quantum methods of "realizing" electrical standards. The most recent papers involving quantum phenomena were published during the past 3 years on investigations of the quantized Hall effect, which will provide a new basis for a definitive standard of electrical resistance. Measurements of power, current, voltage, capacitance, phase angle, and other quantities are also covered. The compilation also includes 16 abstracts of closely related papers by non-NBS authors.

Reference

[1] Precision Measurement and Calibration: Electricity (SP 705), Superintendent of Documents, U.S. Government Printing Office, Washington, DC 20402. (\$23 prepaid. Request stock no. 003-003-02699-9.)

\section{NBS REVISES "MODERNIZED METRIC SYSTEM" CHART}

The metric chart, Modernized Metric System, The International System of Units(SI), has been revised by NBS to include the most recent (1983) definition of the meter. The other base units in the SI systęm include the kilogram (mass), second (time), ampere (electric current), kelvin (temperature), mole (amount of substance), candela (luminous intensity), and two supplementary units, radian (angle), and steradian (solid angle). Each of the units is illustrated and defined on the chart. Tables of common conversions, multiples and prefixes are also included. The revised metric chart is available in two sizes from the U.S. Government Printing Office. A small chart (SP 304a), measuring $11 \times 17$ inches with a brief history of measurement systems, is available in packages of 100 copies for $\$ 50$ prepaid. A larger chart (SP 304), measuring $29 \times 45$ inches, is available for $\$ 2$ a copy prepaid. Order SP 304a by stock no. 003-003-02696-4and SP 304 by stock no. 003-003-02695-6 from the Superintendent of Documents, U.S. Government Printing Office, Washington, DC 20402.

\section{New Services From NBS}

\section{NEW SERVICES GUIDE TO NBS \\ CALIBRATION SERVICES USERS ISSUED}

NBS provides over 300 different calibration and related test services to metrology Laboratories for areas such as dimensional, mechanical, thermodynamic, optical radiation, ionizing radiation, time and frequency, dc and lf electrical, and $\mathrm{rf} / \mathrm{mi}$ crowave measurements. The services are described in the new NBS Calibration Services Users Guide 1986-88, edited by G. A. Uriano et al., and in the supplementary NBS Calibration Services Fee Schedule. For a free copy of these documents or, further information concerning the NBS Calibration Services, contact Ernest L. Garner, Chief, Office of Physical Measurement Services, National Bureau of Standards, B362 Physics Building, Gaithersburg, MD 20899, Telephone 301-921-2805.

\section{NEW LEAK RATE CALIBRATION SERVICE INITLATED}

NBS has established a Special Test Service* for helium permeation leak artifacts in the range $10^{-8}$ to $10^{-11} \mathrm{~mol} / \mathrm{s}\left(2 \times 10^{-4}\right.$ to $2 \times 10^{-7} \mathrm{~atm} \mathrm{cc} / \mathrm{s} @ 0$ $\left.{ }^{\circ} \mathrm{C}\right)$. A Report of Test, which will present the measured value of leak rate over a nominal temperature range of 0 to $50^{\circ} \mathrm{C}$, will be issued for each artifact submitted.

All leak artifacts submitted for measurement must meet the following specifications:

1) Nominal value of helium leak rate of the artifact at room temperature must be between

\footnotetext{
-This Special Test Service involves a measurement or calibration method which is still being perfected and for which all the quality control documentation bas yet to be completed (ref. NBS SP 250 1986-88),
} 


\section{Journal of Research of the National Bureau of Standards}

$10^{-8}$ and $10^{-11} \mathrm{~mol} / \mathrm{s}\left(2 \times 10^{-4}\right.$ and $2 \times 10^{-7}$ atm cc/s@ @ $0^{\circ} \mathrm{C}$.

2) Construction: all-metal reservoir and tubing, of ultra-high vacuum type design, ending in a standard $2.75^{\prime \prime}$ conflat-type flange on the vacuum end, and a sealed helium reservoir.

3) The leak element must be of a sealed glass design, permeable to helium gas, and structurally rugged.

4) An easily observable customer identification number or code must be engraved on the circumference of the $2.75^{\prime \prime}$ flange.

This Special Test Service must be scheduled in advance. To obtain a Test Authorization Number and shipping instructions, send a request stating name, organization, mailing address, telephone number, number of leak artifacts to be evaluated (with nominal leak rates at room temperature in $\mathrm{mol} / \mathrm{s}$ ), and any other pertinent information to Charles Ehrlich, Leak Program Special Test Service, Metrology Building/A55, National Bureau of Standards, Gaithersburg, MD 20899.

The fee for this Service will be at cost, which will be determined at the conclusion of the measurement. Estimated fees will be from $\$ 2,000$ to $\$ 4,000$, U.S., per leak artifact.

For further information, call Charles Ehrlich or Richard Hyland on 301-921-2121.

\section{New Standard Reference Materials*}

\footnotetext{
NEW STANDARD REFERENCE MATERIALS CATALOG AVAILABLE

NBS offers nearly 1,000 different Standard Reference Materials (SRM's) for use in a wide variety of quality control applications in manufacturing, materials production, environmental measurements, and clinical testing. The SRM's are described in the NBS Standard Reference Materials Catalog 198687 , edited by R. W. Seward, and in the supplementary NBS Standard Reference Materials Price List.

For a free copy of these documents or, further information concerning NBS Standard Reference Materials, contact Stanley D. Rasberry, Chief, Office of Standard Reference Materials, National

Bureau of Standards, B311 Chemistry Building, Gaithersburg, MD 20899, Telephone 301-921-2045.

\section{UNALLOYED TITANIUM MATERIALS STANDARDS DEVELOPED AT NBS}

Aerospace scientists, engineers, and others concerned with the purity of unalloyed titanium will find SRMs 650, 651, and 652 useful for validating chemical methods of analysis where solutions are used to determine the quality of metals. The SRMs were requested by industry through ASTM's Special Coordinating Committee S-17, Standard Reference Materials for Metal, Metal Bearing Ores, and Related Materials. The SRMs were certified under the ASTM/NBS Research Associate Program for concentrations of 12 elements and are a graded series with several levels of tungsten. SRM 650 has 1.5 percent tungsten, 651 has 0.4 percent, and 652 has 0.5 percent. The SRMs may be purchased for $\$ 74$ in 30-gram units.

\section{NBS/INDUSTRY DEVELOP MATERIALS STANDARDS FOR ALUMINUM CANS}

Aluminum manufacturers will be interested in a new series of SRMs for analyzing the chemical composition of aluminum alloys used in containers. The standards were developed at NBS after a request by industry through ASTM's Special Coordinating Committee S-17, Standard Reference Materials for Metal, Metal Bearing Ores, and Related Materials. The SRMs were certified under the NBS/ASTM Research Associate Program for nominal concentrations, in percent by weight, for six principal elements. SRMs 1240 and 853 contain 1.1 percent of magnesium and are for analyzing aluminum alloy grade 3004; SRMs 1241 and 854 contain 4.5 percent magnesium and are for analyzing aluminum alloy grade 5182. SRMs 1240 and 1241 , available for $\$ 128$ per disk, are for calibrating optical emission and $x$-ray methods of analysis. SRMs 853 and 854 are fine millings primarily for use in validating wet chemical methods of analysis. They are available for $\$ 83$ in 30-gram units. 